\section{QUALITY OF LIFE OF OMANI WOMEN LIVING WITH GYNECOLOGICAL CANCERS}

${ }^{1} \mathrm{H}$ Al-Awaisi, ${ }^{2}$ Burney, ${ }^{2} \mathrm{M}$ Albalushi*. 'Oman, Muscat, Oman; ${ }^{2}$ Sultan Qaboos University, Sib, Oman

\subsection{6/ijgc-2021-ESG0.583}

Introduction/Background* The vast majority of patients with cancers of uterus, the uterine cervix, and a significant number of patients with cancer of the ovary survive their disease and are considered to be cured. However, the diagnosis of cancer and its treatment can affect quality of life (QoL) adversely. There is no study reporting Qol from Oman and there are only a few studies from Arabic-speaking countries. We report the QoL of Omani women living with gynecological cancers.

Methodology We interviewed 20 Omani women attending the medical oncology clinic in a cancer center in Oman using the validated Arabic version of EORTC QLQ-C30 scale.

Result(s)* The majority of women were married (60\%) with a median age of 40 years, $65 \%$ had ovarian or endometrial cancers, $45 \%$ had at least a baccalaureate and $40 \%$ were working. The majority $(78.9 \%)$ received both chemotherapy and surgery for their treatment. Almost 45\% women had trouble with long walks, needed to take rest, experienced shortness of breath and disturbed sleep, felt tired, had difficulty in concentrating, and felt irritable. However, $80 \%$ rated their overall health as 6 and 7 on a scale ranging from 1 to 7 , with 7 being excellent. Furthermore, $95 \%$ rated their quality of life in the past week as 5, 6 and 7, with 7 being excellent.

Conclusion* The results indicate that despite the physical and social struggle, Omani women who survive gynecological cancers regard their health-related QoL as very good to excellent.

\section{QUALITY OF LIFE AND SEXUAL FUNCTIONING AFTER TREATMENT FOR LOCALLY ADVANCED CERVICAL CANCER - CCRT VERSUS NACT-S}

${ }^{1} \mathrm{M}$ Tahapary*, ${ }^{2} \mathrm{H}$ Toelen, ${ }^{3} \mathrm{M}$ Christiaens, ${ }^{4} \mathrm{E}$ Van Nieuwenhuysen, ${ }^{4} \mathrm{~T}$ Van Gorp, ${ }^{4} \mathrm{R}$ Salihi, ${ }^{4}$ IB Vergote, ${ }^{4} \mathrm{P}$ Neven, ${ }^{4} \mathrm{~S}$ Han. ${ }^{1}$ University Hospital Leuven, Gynaecology and Obstetrics, Leuven, Belgium; ' University Hospital Leuven, Adult Psychiatry, Leuven, Belgium; ${ }^{3}$ University Hospital Leuven, Radiotherapy Oncology, Leuven, Belgium; ${ }^{4}$ University Hospital Leuven, Gynaecological Oncology, Leuven, Belgium

\subsection{6/ijgc-2021-ESG0.584}

Introduction/Background* Locally advanced cervical cancer can be treated by concomitant chemoradiation therapy (CCRT) followed by brachytherapy or by neo-adjuvant chemotherapy followed by surgery (NACT-S). Quality of life (QoL) and sexual health $(\mathrm{SH})$ are important to evaluate after treatment considering the young mean age in affected women and relatively long 5 -year survival. This study aims to compare differences in QoL and $\mathrm{SH}$ among women treated for locally advanced cervical cancer, after CCRT versus NACT-S.

Methodology In this academic single centre cross-sectional questionnaire study, we included patients $>18$ years with a history of locally advanced cervical cancer, who received either CCRT or NACT-S. QoL and SH were assessed using Dutch questionnaires including the European Organization for Research and Treatment of Cancer (EORTC) Quality of Life core module 30 (QLQ-C30), the cervical cancer module 24 (QLQ-CX24), and sexual health questionnaire (SHQ-22). $\mathrm{X} 2$-test and T-test were performed to compare the two groups.

\begin{tabular}{lll} 
Abstract 1109 Table 1 & Clinical variables. \\
\hline & CCRT median (range) & NACT-S median (range) \\
\hline Total number of patients & 12 & 24 \\
Age & $48(33-82)$ & $47(24-71)$ \\
BMI & $24.05(15-32)$ & $25.2(20-39)$ \\
Year of diagnosis & $2013(2008-2018)$ & $2016(2008-2018)$ \\
Partner? & & \\
Yes & 9 & 20 \\
No & 3 & 4 \\
\hline
\end{tabular}

Result(s)* We sent the questionnaires to 105 women who were treated at our centre in the period between 01-01-2002 and 31-12-2018. A total of 36 patients $(34 \% ; n=12$ CCRT; $\mathrm{n}=24$ NACT-S) returned the questionnaire and were included for analysis. Six patients in the NACT-S group also underwent adjuvant CCRT. When comparing the CCRT and NACT-S group, 58\% vs. 54\% did "not at all" feel limited in their daily activities. QoL on average scored 63\% vs. 67\% (P= 0.29), in the CCRT and NACTS group respectively. Patients were at least "quite a bit" or "very much" satisfied with their sex life in $25 \%$ vs. $54 \%$ in the CCRT and NACT-S group, respectively $(\mathrm{P}=0.048)$. A total of $33 \%$ vs. $46 \%$ did "not at all" communicate with medical professionals about sexual issues in the CCRT and NACT-S group, respectively.

Conclusion* QoL did not significantly differ when comparing the CCRT to the NACT-S group. Satisfaction with sexual life was higher in the NACT-S group. QoL and SH should receive more attention in patients with cervical cancer after treatment.

\section{ORTHOTOPIC NEOBLADDER CREATION AFTER CERVICAL CANCER}

${ }^{1} \mathrm{C}$ Ana* ${ }^{2} \mathrm{C}$ Yelo Docio, ${ }^{2} \mathrm{M}$ Fernandez Chereguini, ${ }^{2} \mathrm{~S}$ Alonso, ${ }^{2} \mathrm{~V}$ Corraliza, ${ }^{2} \mathrm{RJ}$ Navarro Avila, ${ }^{2} \mathrm{ML}$ Argente, ${ }^{2} \mathrm{~J}$ De Santiago Garcia. ' MD Anderson, Gynecology Oncology, Madrid, Spain; ${ }^{2} \mathrm{MD}$ Anderson

\subsection{6/ijgc-2021-ESG0.585}

Introduction/Background* Surgery on a radiated pelvis is a challenge for the surgeon due to the scar tissue and loss of anatomical spaces.

After radical surgery it is sometimes necessary to perform a bypass urinary tract, via an ileal conduit, known as Bricker, a continent reservoir or the creation of an orthotopic bladder.

Methodology We are describing the case of a 45 year old pacient, affected of stage IB1 cervical cancer

Wertheim Meigs hysterectomy+ bilateral salpingectomy + selective sentinel lymph node biopsy was performed in another center, followed by chemo-radiotherapy and brachytherapy.

Recurrence is detected at 9 months, describing an implant in right hemipelvis in contact with external iliac vein and bladder wall that compromises the right ureter, conditioning hydronephrosis, mesenteric implant and iliac and inguinal lymphadenopathy.

Months later a vesico-vaginal fistula was observed, and she was referred to our center.

Result(s)* 